\title{
'No Caminho para Casa': ativismo na investigação artística
}

\author{
'In the way home' : activism in Art Education research
}

\author{
Ângela Saldanhai \\ Teresa Torres Eçaii \\ Teresa Medinaiii \\ Faculdade de Belas da Universidade do Porto
}

\begin{abstract}
Resumo
A arte contemporânea permite questionar e refletir sobre as ações sociais e políticas do dia a dia de uma forma ativista, poética e metafórica e responder aos paradigmas atuais, utilizando técnicas performativas híbridas de comunicação e questionamento. Metodologias de investigação usadas nas artes aproximam-se desta contemporaneidade próxima da realidade vigente e apresentam novos caminhos/métodos mais próximos do processo criativo daquele que investiga. A a/r/tografia, aqui apresentada, é um conceito aglutinador de processos artísticos próprios do artista/investigador e professor que reclama uma prática mais próxima de uma Educação Artística, colaborativa e participativa. Este texto é um diálogo entre um exemplo de projeto a/r/tografico e as suas características emancipatórias, ativistas e éticas.
\end{abstract}

\section{Palavras-chave}

A/r/tografia, Ativismo; Emancipação; Ética; Educação artística; Investigação.

\begin{abstract}
Contemporary art allows us to question and reflect in an activist, poetic, and metaphoric way upon daily life social and political actions, and to respond to current paradigms by using hybrid performative techniques of communication and questioning. Research methodologies used in the Arts align to this contemporaneity close to the current reality and present new routes/methods related to the investigator's creative process. The $a / r /$ tography represented here is an agglutinating concept of artistic processes from the artist/investigator and teacher, who claims a practice closer to a collaborative and participative Art Education. This text is a dialogue between an exemplar of an $\mathrm{a} / \mathrm{r} /$ tographic project and its emancipating, activist and ethical characteristics.
\end{abstract}

Keywords

A/r/tography; Activism; Emancipation; Ethics; Art Education; Research.

\section{Introdução}

Nos interstícios entre arte, educação e investigação têm aparecido novas propostas onde as metodologias se imbricam, os campos se diluem e os processos se tornam híbridos. É o caso de muitos investigadores em arte educação que reclamam o conceito aglutinador de a/r/tografia (SALDANHA, 2015; SINNER, 2008; BEER, 1999; SPRINGGAY, 2004) para explicar os seus modos de fazer investigação em educação recorrendo a processos artísticos e colaborativos. A a/r/tografia (a/r/tography, em inglês), desenvolvida por

Revista Digital do LAV - Santa Maria - vol. 8, n. 2, p. 48 - 61. - mai./ago. 2015 ISSN 1983 - 7348 http://dx.doi.org/10.5902/1983734819864 
investigadores da prestigiada Universidade de British Columbia de Vancouver tem sido tão bem aceite por pesquisadores em arte educação, que professores, artistas e investigadores se têm revisto nos seus postulados fortemente influenciados pelos conceitos de experiência de Dewey e de rizoma de Deleuze e Guattari (IRWIN, 2004).

As teorias e práticas a/r/tográficas são situacionistas e multimodais, situando-se num espaço ambíguo e metafórico de clivagem (in-between) onde o uso simultâneo de texto escrito, oralidade, imagens, sons, performances e situações é possível e válido. A investigação é tida como um processo de vivência. Processo onde a poesis, a imaginação e a reflexão sistemática têm papéis fundamentais. Os significados e entendimentos são compreendidos como relacionais, singulares/plurais e rizomáticos. A a/r/tografia, como metodologia de investigação, trouxe um termo legitimador para quem trabalha nos limites da investigação participativa, investigação-ação, investigação narrativa e investigação em educação com base no ativismo, na arte colaborativa ou comunitária, assumindo a arte educação como um campo de questionamento, de reflexão crítica e de intervenção.

\section{A/r/tografia e ativismo na investigação em artes}

Por si só, a a/r/tografia não basta para explicar os processos metodológicos dos investigadores que fazem da sua vida um processo de investigação continua na comunidade através da arte e da educação. No fundo dessas práticas existem procuras ontológicas de libertação e discursos de resistência e de rejeição de valores sociais dominantes como o do individualismo, típico da sociedade de consumo. São investigações baseadas no terreno, com processos relacionais, sociais e situacionais, acabando sempre por ser políticas, e muitas vezes emancipatórias, na medida em que ajudam a construir, retalho a retalho, caminho após caminho, uma metodologia própria, diferente da maioria das teses atuais em educação e um discurso divergente da investigação artística. No âmago desses processos de investigação ativistas, ligados à comunidade, à arte e à educação, estão também metodologias de investigação participativa aliadas a conceitos de arte contemporânea que iremos descrever mais tarde.

A investigação participativa integra e combina a investigação social, o trabalho educativo e a ação com objectivos de transformação estrutural e de melhoria de vida dos sujeitos implicados (HALL \& KASSAM, 1985). É uma metodologia de análise e de intervenção que parte da ação-reflexão de Freire (1997) e da sua teoria da educação e da ação

Revista Digital do LAV - Santa Maria - vol. 8, n. 2, p. 48 - 61. - mai./ago. 2015 ISSN 1983 - 7348 http://dx.doi.org/10.5902/1983734819864 
cultural e que tem vindo a adaptar-se a outros contextos, assumindo a comunidade como principal agente de mudança e de transformação da sua realidade. Segundo Goméz, Freitas e Callegas é uma estratégia suscetível de contribuir para o desenvolvimento comunitário, enquanto processo sistémico, permitindo às comunidades um conhecimento mais profundo dos seus problemas e capacitando-as para a sua resolução (GOMÉZ et al., 2007).

Como contraponto ao elitismo dos espaços fechados do mercado da arte, galerias, museus, centros culturais e outros lugares, legitimados pelos críticos de arte e comerciantes de obras de arte, muitos coletivos de artistas e grupos ativistas, nas últimas décadas, têm trabalhado em outros lugares - site specific, nos bairros, nas cidades, com a colaboração das comunidades residentes. Entre esses artistas alguns destacam-se porque, nas suas propostas, não buscam apenas relatar experiências mas propõem formas de trabalho explicitamente sociais e políticas. O objetivo dos seus projetos não é somente promover ou provocar relações sociais, mas, e sobretudo, intervir em contextos determinados para terem um impacto social e político que traga algo de positivo para as comunidades com quem trabalham. Tais práticas têm sido descritas com variados termos - contextuais, situacionais, dialógicas ou colaborativas (SANSI, 2013, p. 13), community applied arts (JOKELA et al.), ativistas (AGRAPARDIÑAS, 2013). Interessa-nos aqui, sobretudo, o sentido de arte educação ativista que Maria Jesus Agra-Pardiñas traz para a educação, utilizando processos artísticos da arte contemporânea que tendem a documentar, provocar ações ou situações potenciadoras de um questionamento sistemático das identidades e das relações interpessoais.

Comum a todas essas práticas existe um denominador: a generosidade, a partilha e o retorno à comunidade. $E$, esse aspecto, faz com que as ações desenvolvidas sejam um motor de mudança social. Mais importante do que autorias partilhadas, elas comportam micro-utopias susceptíveis de despoletar consciências e movimentos e de gerar outras ações. No centro dos processos estão situações de "dádiva onde o investigador/artista oferece o seu trabalho à comunidade, construindo com ela processos artísticos e educativos participativos e transformadores da realidade e das dinâmicas sociais existentes.

Si on donne les choses et les rend, c'est parce qu'on se donne et se rend «des respects»- nous disons encore « des politesses ».

Revista Digital do LAV - Santa Maria - vol. 8, n. 2, p. 48 - 61. - mai./ago. 2015 ISSN 1983 - 7348 http://dx.doi.org/10.5902/1983734819864 
Mais aussi c'est qu'on se donne en donnant, et, si on se donne, c'est qu'on se « doit » - soi et son bien - aux autres (MAUSS, 1924, p.66).

Criam-se situações relacionais complexas. O trabalho artístico expande os limites do que, no ocidente, se tende a considerar arte, sobretudo o conceito de arte que surgiu na idade moderna, um campo de atividades que implica a produção de obras validadas e com valor de mercado. Na perspetiva que temos vindo a desenvolver, os artistas utilizam os processos artísticos para fins sociais, tendendo, cada vez mais, a cruzar-se, numa lógica transdisciplinar, com os campos da antropologia e da etnografia, mas também da história, da sociologia e da educação.

Joseph Kosuth (1975), quando escreveu Artist as Anthropologist (1975), considerava que tanto o artista como o antropólogo lidavam com questões culturais - 'cultural fluency', num exercício crítico sobre o conhecimento do quotidiano (KOSUTH, 1975, p.182-85). Investigadoras ativistas, como Maria Jesus Agra Pardiñas, utilizam processos artísticos que integram variadíssimas disciplinas e baseiam as suas práticas na 'performance' como ação no quotidiano e como estratégia para um método de pesquisa. $O$ interesse pela performance, que nas artes visuais surgiu nos anos 50 e 60 do século XX, não é exclusivo das artes, estando igualmente presente em áreas da filosofia e das ciências sociais (KLIMKE e SHARLOOTH, 2009).

Os investigadores/artistas e professores que se assumem como ativistas na educação e na arte revêm-se nas teorias da estética relacional (BOURRIAUD, 2002), da educação como emancipação (FREIRE, 1973) e como promessa de um futuro sustentável (MORIN, 1999) e em práticas de movimentos artísticos, como os situacionistas, que articulavam a arte com a investigação social e o ativismo político (INTERNACIONAL SITUACIONISTA, 1960).

Os situacionistas criaram métodos de pesquisa e de ação que marcaram gerações de artistas. Métodos ainda hoje presentes em intervenções críticas à sociedade de consumo e em propostas alternativas aos discursos do poder, sendo referentes significantes nos artistas, nos educadores e nos investigadores ativistas que trabalham no campo da arte educação. Processos como 'détournement', 'situations' e 'derives', constituíram-se em novos meios para documentar, questionar e mapear o quotidiano.

Revista Digital do LAV - Santa Maria - vol. 8, n. 2, p. 48 - 61. - mai./ago. 2015 ISSN 1983 - 7348 http://dx.doi.org/10.5902/1983734819864 
Segundo Miwon Kwon, os artistas que trabalham com comunidades correm dois riscos antagónicos: podem transformar a comunidade num ready-made ou desaparecer como artistas e transformarem-se em assistentes sociais (KWON, 2012, p.17). O primeiro caso acontece muitas vezes, quando o artista procura apenas o registo da situação, a análise documental, através de processos artísticos, para fabricar a sua narrativa pessoal que poderá, depois, ser validada nos mercados como obra de arte. No segundo caso, os artistas não são, normalmente, reconhecidos como tal e as obras (ações) por eles despoletadas nunca, ou raramente, são validadas pelo círculo restrito que define o que é arte e não arte nos circuitos oficiais da cultura. Na investigação em arte educação interessam-nos sobretudo as práticas do segundo grupo de artistas, os quais não se limitam a documentar um fenómeno ou uma realidade específica num determinado contexto, ou a criar obra com a ajuda de participantes não artistas. O que torna específico este tipo de arte é a sua hibridez, a sua capacidade de diálogo e de respeito pelos outros, na medida em que o artista deixa de ser protagonista e passa a ser um facilitador, alguém que oferece o seu trabalho para a comunidade, como uma microutopia, dentro do conceito da 'estética relacional' (BOURRIAUD, 2002). Ao oferecer o seu trabalho, o seu engenho e arte, o artista oferece-se numa relação única de comprometimento mútuo, tal como Mauss a descreveu (MAUSS, 1924, p.66), sem deixar de ser artista.

Nous avons vu la science, la technique, l'industrie révéler leurs ambivalences. Et l'avenir du monde est orphelin de ce futur promis. Or rien n'est possible sans un redressement de l'espérance. Mais il ne s'agit pas de recoller les morceaux de l'ancienne promesse du salut terrestre. Il s'agit de créer une espérance qui affronte les défis, qui sait qu'elle peut échouer et qui compte sur la prise de conscience et de responsabilité." (MORIN, 2008 , no seu discurso de abertura das celebrações dos 50 anos dos "Cahiers pédagogiques")

Investigadores ativistas que, neste momento, trabalham com comunidades, nas fronteiras da arte e da educação, utilizando processos artísticos que relevam metodologias híbridas, como a a/r/tografia e a investigação participativa, estão a romper limites na arte educação até agora considerados estanques. Trilhando caminhos da investigação ativista em arte educação centram-se em colectivos de pessoas, não em indivíduos isolados, perseguem objectivos de potenciação e desenvolvimento local e comunitário, realizam atuações nas comunidades ou contextos em que se geram as problemáticas a resolver e não em ambientes institucionais separados, trabalham a partir

Revista Digital do LAV - Santa Maria - vol. 8, n. 2, p. 48 - 61. - mai./ago. 2015 ISSN 1983 - 7348 http://dx.doi.org/10.5902/1983734819864 
das histórias de vida dos elementos grupo, das suas vivências, necessidades e recursos. Este modo de fazer investigação permite delinear uma nova figura de artista/educador/investigador que aparece, indubitavelmente, como mediador comunitário, como elo gerador de situações de compromisso e de mudança, intrinsecamente construídas com as pessoas e com as comunidades. Uma nova figura que_ trabalha por retalhos, multidisciplinarmente, que promove a comunidade, a participação e a integração social em contraponto ao isolamento e à desagregação, susceptível de influenciar as instituições educativas e culturais que, por si só, não são capazes de criar uma alternativa sustentável, e intervindo para construir uma promessa de futuro com gente dentro.

\section{O projeto "No caminho para casa"}

Tendo por base muitos dos pressupostos atrás enunciados, o projeto "No caminho para casa: um estudo artográfico de recolha de memórias numa comunidade informal", desenvolvido no âmbito de um Doutoramento em Educação Artística, pretendeu alargar os horizontes, normalmente praticados na educação artística em Portugal, aos "entrelugares" de Irwin (2004), em que todos vivemos.

A $A / r /$ tografia, como aglutinadora de metodologias usadas na área das artes, como potenciadora de diálogo, de trabalho conjunto e participativo, revelou-se fundamental e basilar em todo o processo.

A consciência que vivemos nos entre-lugares da arte (artist), da investigação (researcher) e da educação (teacher) e que estes se articulam permite-nos uma relação e reflexão mais honesta sobre aquilo que nos rodeia.

Viver no desconchego da investigação, consente a paixão, a hibridez das linguagens e tudo que é próprio à vida - à vida de quem investiga. $\mathrm{A} a / \mathrm{r} /$ tografia permite arriscar, às vezes demasiado, e faz-nos pensar constantemente que poderíamos ir ainda mais além.

Colocarmo-nos numa perspetiva artográfica implica trabalhar no sítio em que vivemos, rejeitar a possibilidade de dividir vidas, viver apaixonado e angustiado, constantemente. Não há possibilidade de entrar em casa e deixar a investigação no lugar dela, porque a própria casa é também lugar de investigação.

Os a/r/tográficos trabalham a vida, a sua relação com o mundo e a forma como se vêem

Revista Digital do LAV - Santa Maria - vol. 8, n. 2, p. 48 - 61. - mai./ago. 2015 ISSN 1983 - 7348 http://dx.doi.org/10.5902/1983734819864 
no mundo - "Living Inquiry" (Pesquisa viva), trabalham em conjunto com a sua prática e nos entre-lugares da sua existência. Preocupam-se com as relações e o impacto das suas ações na sua vida e na do "outro". Não conseguem dividir o privado e o público, a sua profissão e a sua vida pessoal. Não tiram férias da sua investigação, pois ela está intimamente ligada ao caminho que trilham no dia a dia. Vivem no desconforto da intersubjetividade dos lugares, criando e recriando questões.

A a/r/tografia parte da vida para a vida, habita nos entre-lugares da nossa existência e relaciona a teoria com a prática, arte e grafia e as nossas diversas identidades ("Contiguidade"). Os a/r/tográficos usam a metáfora e a metonímia para dar forma às emoções e sentimentos, trabalham em conjunto em ações participativas e colaborativas. As aberturas ("Openings") surgem nos entre-lugares e apresentam-se como "luzes" no confronto entre lugares, metaforicamente representam aquilo que vemos para além do real.

As "Reverberações" representam o movimento, o dinamismo entre as conexões, e o "Excesso" alerta-nos para a importância do excedente, do que é deixado de parte, para o que normalmente é rejeitado ou ignorado. Esta forma de estar na vida leva-nos a criar novos significados e lugares, encorajando a provocação, o híbrido, o questionamento e a constante mutação.

O projeto "No caminho para casa" defende, assim, o processo, os lugares em aberto, os caminhos percorridos, coletivamente e a continuação de uma vida em comum, para além das exigências académicas.

Uma investigação narrativa, biográfica e auto-biográfica, com métodos próprios de um processo criativo que permite a participação coletiva, de autoria partilhada e sustentada, que emancipa a comunidade que nela participa.

Este projeto, que decorre numa comunidade de Gulpilhares, V.N. de Gaia, Portugal é, assim, um projeto de ativismo, de criação, de partilha e aprendizagem conjunta, que se inicia numa comunidade informal, uma mercearia, com a sua proprietária, a Avó Miquinhas e as suas narrativas de vida. Nestas narrativas surgem outras pessoas, pertencentes à mesma comunidade, que também partilham as suas histórias de vida, criando um grupo base de ação que inquieta.

Revista Digital do LAV - Santa Maria - vol. 8, n. 2, p. 48 - 61. - mai./ago. 2015 ISSN 1983 - 7348 http://dx.doi.org/10.5902/1983734819864 
O projeto desenvolve-se próximo da realidade projetual, em que as imagens estáticas e dinâmicas, as diferentes fontes tipográficas, as metáforas, as configurações das páginas e as suas texturas fazem parte do percurso, de forma coerente e sólida, na poesia que é a vida.

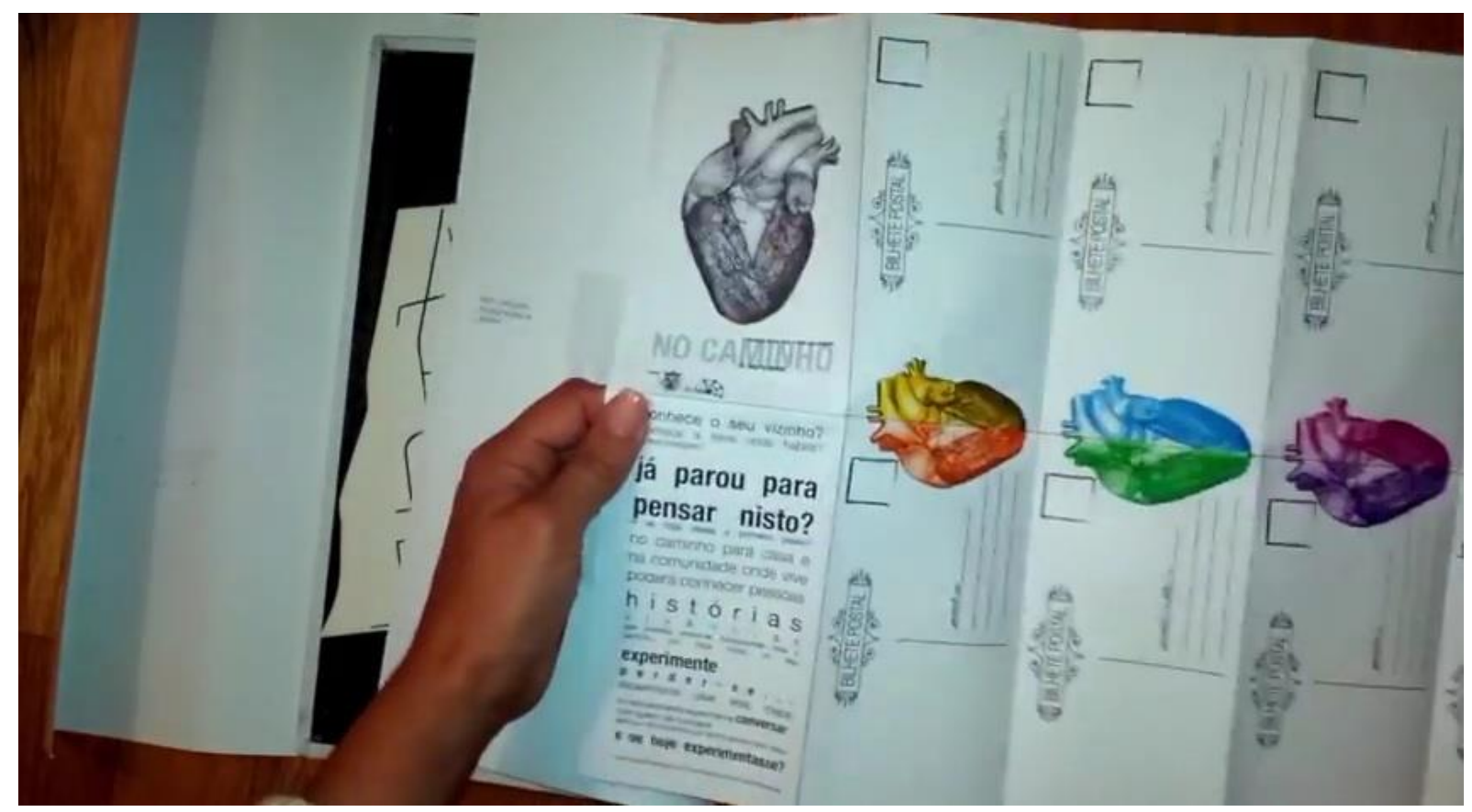

Figura 1: Objeto-tese "No caminho para casa - um estudo artográfico de recolha de memórias numa comunidade informal"

(https://www.youtube.com/watch?v=5Gqh7nHMKks)

A intensidade e as emoções transmitidas na palavra escrita dificilmente passam para o recetor com a monotonia do traço. Os registos sensoriais não servem para ilustrar, mas para provocar. Os cheiros, as pessoas, as cores, os movimentos, os gestos, as palavras, as histórias, os objetos, as entrelinhas, os silêncios... Os saberes tradicionais que nos são passados, oral e visualmente, como a agricultura, a cozinha, o tricô ou o crochet, apesar de estarem disponíveis em livros ou suportes digitais, não têm aí a mesma magia de quando crescem connosco. As mãos enrugadas e aparentemente frágeis da avó a amassar o pão ou a paciência do tricotar, do fazer e desfazer... elevam-nos a um patamar ao qual só os nossos passos, o nosso caminho, o nosso olhar nos podem conduzir. O tricotar como lugar de pensamento, de reflexão, de construção da tese, do pensar a tese, do pensar a vida, surge neste lugar como elemento fundamental para o seu desenvolvimento. Faz parte dela...

Revista Digital do LAV - Santa Maria - vol. 8, n. 2, p. 48 - 61. - mai./ago. 2015 ISSN 1983 - 7348 http://dx.doi.org/10.5902/1983734819864 
O lugar meditativo, que só quem faz tricot compreende, faz movimentar o corpo e organizar as ideias. Semelhante à construção de uma mandala. Organiza os caminhos e apazigua o silêncio ou a urgência da escrita.

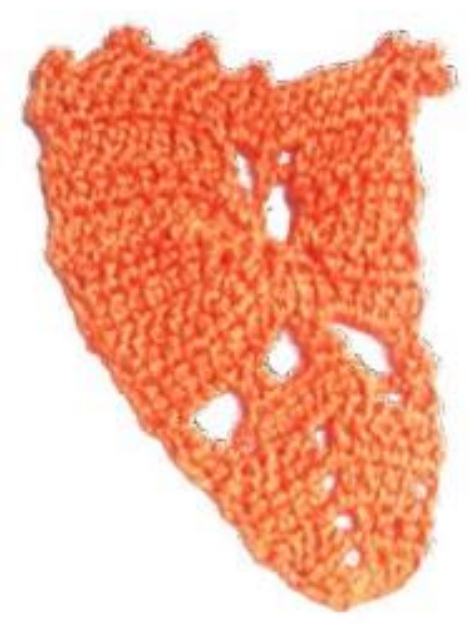

Figura 2: Coração de tricô oferecido à comunidade

Conversas, cheias de narrativas que cruzam constantemente a história da Avó Miquinhas, com a da Mercearia, com a história da comunidade e do país, fazem querer conhecer outras e multiplicar os atores, constantemente.

Revista Digital do LAV - Santa Maria - vol. 8, n. 2, p. 48 - 61. - mai./ago. 2015 ISSN 1983 - 7348 http://dx.doi.org/10.5902/1983734819864 


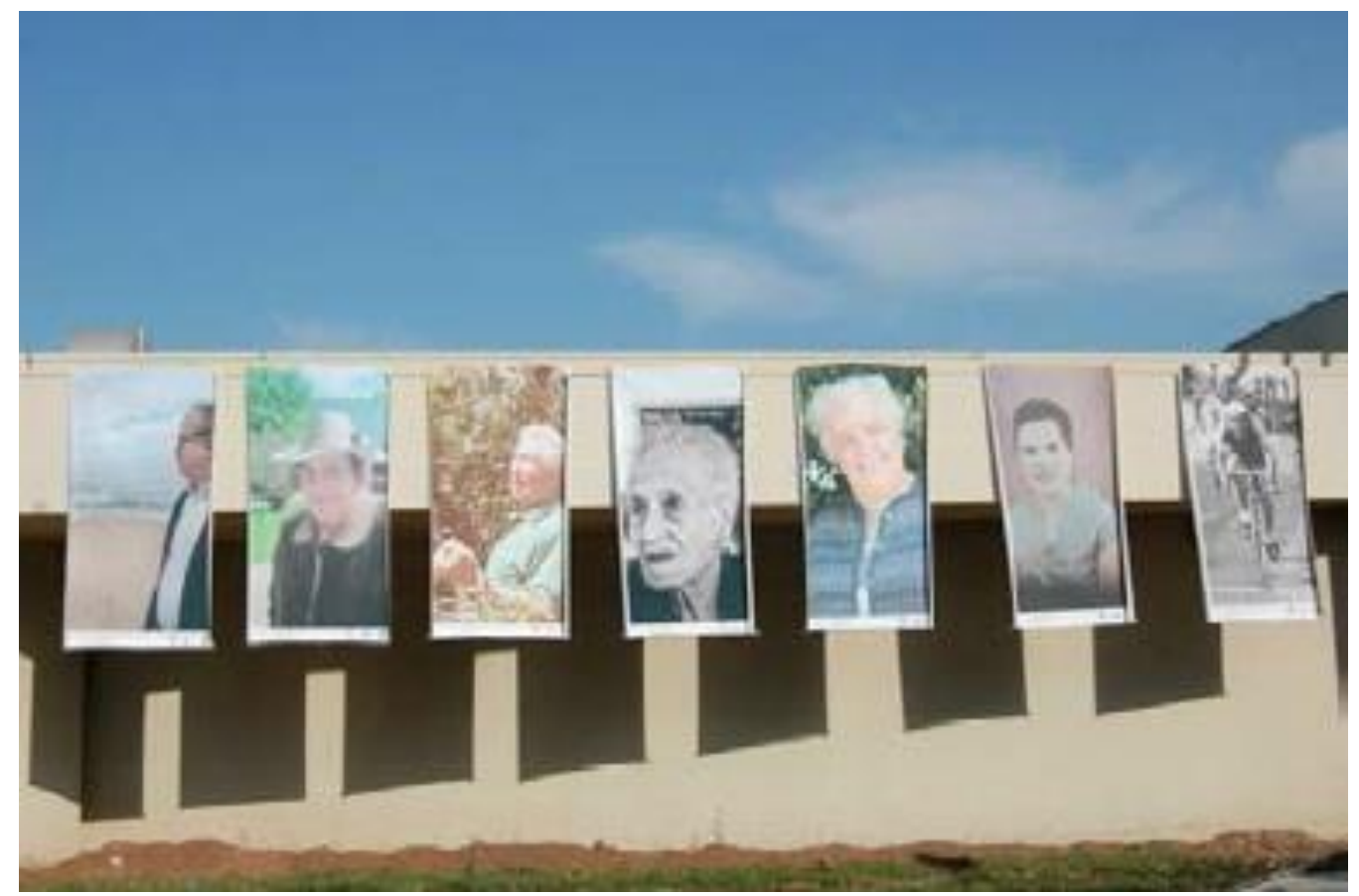

Figura 3: As fotografias 7 intervenientes iniciais (escolhidas pelos próprios) expostas na comunidade

O projeto é um estudo de raiz a/r/tográfica que valoriza o que é dito nas entrelinhas, o que acontece nos entre-espaços e o uso das metáforas, das imagens e da poesia, sendo dada ênfase à imagem e àquilo que recorre aos sentidos sensoriais, não como ilustração, mas como parte integrante e essencial do trabalho, como objeto dialogante.

Tudo isto concorre para a procura de uma história do caminho, de uma cartografia própria, que não conte somente narrativas pela oralidade ( 7 intervenientes iniciais), mas que enriqueça essas histórias com imagens, objetos (escolhidos pelos 7 intervenientes iniciais), os lugares da comunidade que elas mais mencionam como referências (7 lugares) e as obras de arte - objeto síntese da vida de cada um dos 7 intervenientes, que relaciona não só as narrativas a que $7+7$ artistas tiveram acesso (conversasvídeo), mas a vida de cada um destes outros que percorrem outros caminhos e que, mesmo noutras comunidades, se relacionam com a nossa.

Uma triangulação de variáveis que se complementam num só mapa, onde todos os sentidos são evocados:

- as 7 narrativas de vida (oralidades, imagens e objetos) de cada um dos intervenientes iniciais;

Revista Digital do LAV - Santa Maria - vol. 8, n. 2, p. 48 - 61. - mai./ago. 2015 ISSN 1983 - 7348 http://dx.doi.org/10.5902/1983734819864 
- os 7 lugares da comunidade mais vezes mencionados nas conversas iniciais (retratados por outras 7 pessoas, ou grupos de pessoas, da comunidade, em forma de som);

- os 7 artistas da comunidade que realizam uma obra de acordo com as narrativas ouvidas, mas também de acordo com as suas próprias vivências da comunidade;

- outros 7 artistas, de fora da comunidade, que concretizam outra obra sobre as mesmas narrativas, mas de acordo com as suas vidas, vividas fora desta comunidade.

- a devolução à comunidade de fragmentos da sua história e das vidas que a foram construindo, um momento de partilha, de afetos, de valorização das pessoas e de construção conjunta de novos laços e de novos desafios

- as potencialidades abertas para outros olhares e modos de ser e estar em comunidade
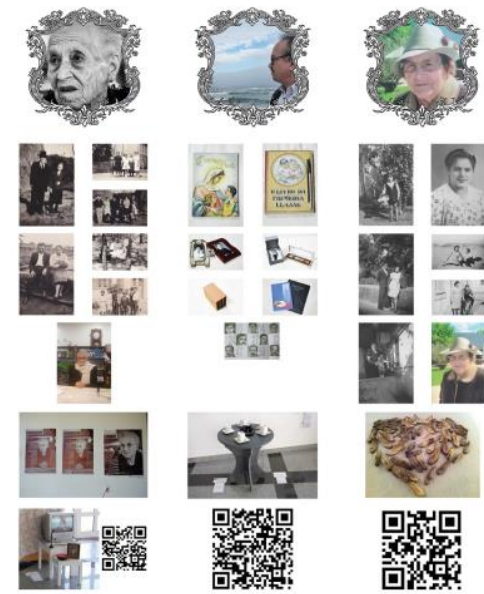
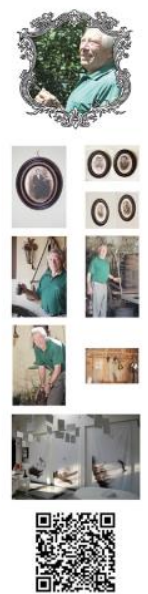
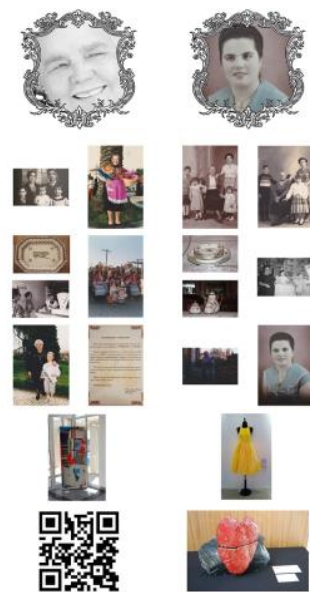
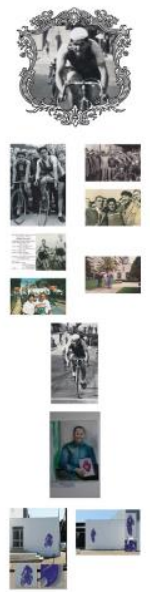
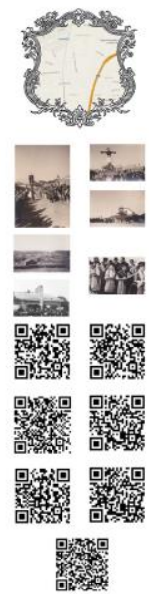
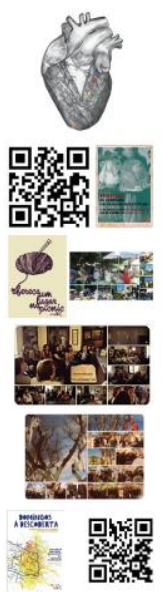

Figura 4: Novo mapa - triangulação de variáveis (conclusões do trabalho "No caminho para casa - um estudo artográfico de recolha de memórias numa comunidade informal")

O projeto defende, assim, a diversidade (abrindo as portas aos outros, ao respeito pela sua história pessoal, sonhos e desejos), o respeito mútuo (consideração pelo tempo e espaço de cada um) e um olhar conjunto para aquilo que nos rodeia (reflexão de acordo com os vários pontos de vista que compõem este trabalho e um caminho trilhado de acordo com os desejos dos intervenientes), constituindo-se como elementos base que impõem uma maior atenção ao percurso e nos obrigam a caminhar de acordo com as sinergias próprias do meio que estabelece as suas próprias regras, habitualmente distantes daquilo a que as "grandes massas" estão acostumadas.

\section{Notas Finais}

O percurso iniciado com o projeto "Um caminho para casa" prossegue, construído conjuntamente por muitas pessoas que, numa rede comunitária, vão tecendo uma teia

Revista Digital do LAV - Santa Maria - vol. 8, n. 2, p. 48 - 61. - mai./ago. 2015 ISSN 1983 - 7348 http://dx.doi.org/10.5902/1983734819864 
em que se multiplicam os "Domingos à descoberta", os piqueniques comunitários, os encontros de "Tricoteia", as sessões de cinema, as horas do conto e tudo o mais que para alguém faça sentido e queira desenvolver.

Um caminho que nasceu na comunidade, que nele se constrói e alicerça, acreditando nas pessoas que a constituem e nas suas potencialidades. Um caminho percorrido em conjunto e que todos sentem como seu, independentemente da idade, nível de escolaridade ou atividade profissional, partilhando afetos, vivências, conhecimentos e saberes, aprendendo e ensinando, questionando, decidindo e construindo um novo futuro colectivo. Um caminho que, deste modo, se constitui como um novo desafio à escola e à educação artística, permitindo equacionar outros modos de pensar a arte educação e as suas potencialidades no trabalho com as comunidades e no desenvolvimento destas enquanto espaços emancipatórios de resistência e de liberdade.

\section{Referências}

AGRA-PARDIÑAS, Maria Jesus. Historias en torno al arte $y$ a la educación artística: Notas para un posible diario. Caleidoscopio: Santiago de Compostela. 2012.

BEER, R. Landscape and identity: Three artist/teachers in British Columbia. Vancouver, BC: The University of British Columbia. 2012. Disponível em: <http://artography.edcp.educ.ubc.ca/?page_id=117>. Acesso em: 4/05/2015.

BOURRIAUD, N. Relational Aesthetics. Dijon: Les Presses du Réel . 2002.

FREIRE P. Ação cultural para a liberdade. $2^{a}$ ed. São Paulo (SP): Paz e Terra; 1997.

GOMÉZ, J.A.C.; Freitas, O.M.P.; Callegas, G.V. Educação e Desenvolvimento Comunitário Local: Perspectivas Pedagógicas e Sociais da Sustentabilidade. Porto: ProfEdições, 2007.

HALL \& KASSAM. Participatory Research. Em : Husen, T e Postlethwaite, T.N. (eds.) : The International Enciclopedia of Education. Oxford: Pergamon Press, 1985, 3795$3800 \mathrm{p}$.

IRWIN, R. \& de COSSON, A. (Eds.). A/r/tography: Rendering self through Arts Based living inquiry. Vancouver: Pacific Educational Press. 2004.

Revista Digital do LAV - Santa Maria - vol. 8, n. 2, p. 48 - 61. - mai./ago. 2015 ISSN 1983 - 7348 http://dx.doi.org/10.5902/1983734819864 
JOKELA. J.; GLEN COUTTS, G.; HARKONEN E.; HUHMARNIEMI M. Cool: Applied Visual Arts in the North. University of Lapland, 2013.

INTERNACIONAL SITUACIONSITA 4, (1960). Manifesto. Disponível em: <http://guydebord.blogspot.pt/2009/06/manifesto-internacional-situacionista.html>Acesso em: 4 maio. 2015.

KLIMKE, M. \& SHARLOOTH, J. Utopia in practice the discovery of performativity in sixties Protest, Arts and Sciences. In A. Diall, V. Karamanoakis, and K. Kornetis (Eds.) Historicizing 1968 and the Long Sixties. Athens, Historein, Vo.9. 2009. 46-56 p.

KOSUTH, J. \& WESTWOOD, P. Art after philosophy and after: collected writings, 1966-1990. Cambridge, Mass., MIT Press. 1991. Disponível em: <http://www.vizkult.org/propositions/alineinnature/pdfs/Kosuth-ArtistAsAnthropologistexcerpts.pdf>. Acesso em: 4/05/2015.

KWON, M. (2002). One Place After Another: Site Specific Art and Locational Identity. Cambridge: MIT Press.

MAUSS, M. (1924), Essai sur le don. Forme et raison de l'échange dans les sociétés archaïques. I'Année Sociologique, seconde série, 1923-1924. Disponível em: <http://classiques.uqac.ca/classiques/mauss_marcel/socio_et_anthropo/2_essai_sur_le_ don/essai_sur_le_don.html >.Acesso em: 4/05/2015.

MORIN, E. (1995). Pour penser l'éducation de demain. Discurso da abertura dos 50 ans des Cahiers pédagogiques. Paris, 1995.

Disponível em: <http://www.cahiers-pedagogiques.com/Pour-penser-l-education-dedemain>. Acesso em: 4/05/2015.

MORIN, E. Les sept savoirs nécessaires à l'éducation du futur. UNESCO. 1999 Acessível em Disponível em: <http://unesdoc.unesco.org/images/0011/001177/117740fo.pdf>.

Acesso em: 4/05/2015.

SALDANHA, A. No caminho para casa - um estudo a/r/tográfico de recolha de memórias numa comunidade informal. Faculdade de Belas Artes da Universidade do

Revista Digital do LAV - Santa Maria - vol. 8, n. 2, p. 48 - 61. - mai./ago. 2015 ISSN 1983 - 7348 http://dx.doi.org/10.5902/1983734819864 
Porto. 2015.

SANSI, R. Art, Anthropology and the Gift . London: Bloomsbury, 2015.

SINNER, A. Unfolding the Unexpectedness of uncertainty: Arts research as a

triptych installation: A conversation of processes, practices, products. Vancouver: The University of British Columbia, 2008. Disponível em: <http://artography.edcp.educ.ubc.ca/?page_id=117>. Acesso em 4/05/2015.

SPRINGGAY, S. Inside the visible: Youth understandings of body knowledge through touch. Vancouver, BC: The University of British Columbia. 2004. Disponível em: <http://artography.edcp.educ.ubc.ca/?page_id=117>. Acesso em: 4 maio. 2015.

\footnotetext{
${ }^{i}$ i2ADS Instituto de investigação em arte, design e sociedade - Doutoranda do Programa Doutoral em Educação da Faculdade de Belas Artes da Universidade do Porto.

ii i2ADS Instituto de investigação em arte, design e sociedade - Faculdade de Belas Artes da Universidade do Porto. Presidente da InSea.

iii CIIE - Centro de Investigação e Intervenção Educativas - Faculdade de Psicologia e Ciências da Educação da Universidade do Porto.
}

Recebido em: 30 de abril de 2015

Aprovado em: 31 de julho de 2015

Revista Digital do LAV - Santa Maria - vol. 8, n. 2, p. 48 - 61. - mai./ago. 2015 ISSN 1983 - 7348 http://dx.doi.org/10.5902/1983734819864 